\title{
Drawing therapy to improve the quality of life for children victims of landslides
}

\author{
Elli Nur Hayati ${ }^{1}$, Inda Purwasih ${ }^{2}$, Siti Urbayatun ${ }^{3}$ \\ ${ }^{1,2,3}$ Post Graduate Program on Profesional Clinical Psychology, Universitas Ahmad Dahlan. \\ ${ }^{2}$ Universitas Islam Negeri Raden Fatah Palembang, Indonesia \\ ${ }^{1}$ elli.hayati@psy.uad.ac.id, ${ }^{2}$ indapurwasih0890@ gmail.com, ${ }^{3}$ siti.urbayatun@psy.uad.ac.id
}

\section{ARTICLE INFO}

Article history

Received 27 October 2017

Revised 1 February 2019

Accepted 14 February 2019

Keywords

children survivors of a landslide disaster

drawing therapy

quality of life

\begin{abstract}
Disasters may affect the quality of life of survivors, including children. Therefore, interventions that may improve survivors' quality of life is needed. The purpose of this study is to determine the effect of drawing therapy in improving the quality of life of children survivors of landslides in Purworejo, Central Java, Indonesia. This study used a quasi-experimental design with one group pretest - posttest. The subjects were five children aged 8 to 11 years who experienced a landslide disaster, and had low or moderate quality of life based on WHOQOL-BREF scale categorization. The experimental group was treated using therapeutic techniques that facilitated the subject to externalize their traumatic experiences through creative actions that reflected their feelings and thoughts. Therapy was done through three stages of warm up, mindfulness, and drawing. The results of the Friedman Test analysis show the differences in the quality of life scores in all domains before and after the intervention was given. Qualitative data that was taken as complimentary to the quantitative part also showed a description of improved behavior, attitudes, and social interactions among the children. It is concluded that drawing therapy can improve the quality of life of the children survivors of a landslide disaster.
\end{abstract}

\section{Introduction}

Indonesia is one of the countries in the world prone to natural disasters according to the United Nations International Strategy for Disaster Reduction ("UNISDR," n.d.). Various natural disasters starting from earthquakes, tsunamis, volcanic eruptions, floods, landslides, droughts, and prone forest fires are prone to occur in Indonesia. Even for some types of natural disasters, Indonesia ranked first in exposure to the population or the number of people who were victims of natural disasters. This is what brings Indonesia as a country with the highest risk and impact of natural disasters in the world ("UNISDR," n.d.). The National Disaster Management Authority (BNPB) made a recapitulation of various disaster events in Indonesia, and the results showed that the number of disasters in 2016 reached 2,342 and this was the highest frequency since 2002 ("Data Informasi Bencana Indonesia (DIBI)," n.d.). Of the total number of disasters, 92\% were hydro-meteorological disasters, i.e. rain (including rainstorms) which caused floods and landslides.

Natural disasters have caused mental health problems for people who are exposed to it, especially in vulnerable groups such as women, the elderly, children and poor families 
(Somasundaram \& Van de Put, 2006). A review of the impact of natural disasters on children conducted by Kar (2009) shows that mental and behavioral symptoms occured and have the potential to take place in a prolonged manner, after the children experience natural disasters. The most common mental health symptoms experienced by children are acute stress reactions, adjustment disorders, depression, panic disorder, PTSD, childhood anxiety disorders, and phobias (Kar, 2009). Living a life with such a mental situation is of course very disturbing and affecting the quality of life of the children in general. A post-earthquake study performed on a total of 586 children aged 8-16 in Sichuan showed that in the 15 months after the earthquake, $12.4 \%$ of them had PTSD and had low scores on their quality of life (Jia et al., 2010)

Landslides in the village of Jelok, Kaligesing sub-district, Purworejo Regency, in Central Java have had an impact on the community, including children in the region. The results of the initial assessment of the children's social situation in the region showed a decrease in the quality of life of children as those who previously seemed cheerful, actively interacting socially and productively in learning, had changed dramatically to the contrary after experiencing a landslide. After the disaster, they become quiet, anxious, and rarely interact to play together for fear of a future disaster.

Quality of life is an individual's perception of the position of the person's life in the culture and value system where the person lives and in relation to the person's hopes, goals, and standards of living (WHO, 1997). The concept has a broad scope, which is complexly influenced by physical health, psychological conditions, the level of independence, social relations, personal beliefs, and their relationships with the important things in their environment (WHO, 1997). Therefore, from the beginning of its formulation, WHO determined how quality of life can be measured, i.e. by evaluating a person's physical, psychological, social and environmental aspects (WHO, 1996). So far it has been difficult to find a study of quality of life among children, especially for measuring quality of life, except for children with chronic diseases (Eiser \& Morse, 2001; Varni, Seid, \& Rode, 1999; Varni, Limbers, \& Burwinkle, 2007). This is because the quality of life is measured based on one's perceptions of several aspects of their life, so measuring the quality of life in children requires assistance from parents in answering questions on the various aspects revealed in the concept of quality of life (Eiser \& Morse, 2001).

Children who experience fear due to trauma from disasters usually tend to have difficulty in expressing their feelings, so they need to be facilitated with the appropriate methods to help them. The main treatment method for traumatized children is often a combination and not a single treatment, for example, besides involving children, it also involves parents or a group of other children. The treatment method also differs for each age group, e.g. for pre-school age the treatment is more focused on playing, while for school age playing and drawing are combined with discussions, and for adults it is more often focused on discussion with role playing (Nader, 2004).

Drawing therapy is a treatment method that can be applied to children. Drawing therapy is defined as one way to connect memory disassociation and regain consciousness, after a traumatic experience is translated into the form of a story, and re-integrate past, present, and future experiences (Malchiodi, 2005). Drawing therapy provides an opportunity for the participants to communicate feelings, thoughts, problems, hopes, and dreams in a safe way, because in drawing activities there are no judgments (good/bad, wrong/right), and participants can convey anything about the images they make freely (Buchalter, 2009). According to Chilcote (2007), art therapy, especially drawing, is quite effective in reducing posttraumatic stress disorder. Besides, drawing therapy can be applied culturally as an intervention for children because art is universal, and children are better 
prepared to share their trauma, which they have long kept for themselves since their traumatic incidents. Malchiodi (2001) also states that drawing therapy is able to facilitate the disclosure of emotions of children who are traumatized, without them having to express it verbally.

Drawing therapy can facilitate individuals to reduce anxiety and help them feel comfortable, integrate the functions of the left and right brain, activate the limbic system that functions to process emotions, feelings, memory about traumatic things to encourage the left side of the brain to design creative ideas, so when the client participates in an art therapy and performs the drawing process, the image is usually a picture of the memories they have experienced (Talwar, 2007). The study performed by Madden, et al. (2010) on the use of creative arts therapy (CAT) for pediatric patients with brain tumors shows that CAT can improve the quality of life in children who has brain tumor in undergoing chemotherapy.

The above discussions provide an understanding that drawing therapy is a psychosocial intervention technique that can be used to help individuals express their feelings, thoughts, and creativity, so they become a means of externalizing the traumatic experiences lived by the individuals. This current study hypothesizes that drawing therapy may improve the quality of life in children affected by landslides in Purworejo.

\section{Method}

\section{Research Design}

This study used a quasi-experimental design with one pretest - posttest research design model. This design aims to see the effect of a treatment on the experimental group, so the results of the treatment can be identified more accurately because it can be compared with the situation before the treatment was given. Qualitative data is also used in this experimental research as complimentary data.

The study was conducted in one group of children, i.e. the experimental group, which was given a treatment in the form of drawing therapy that was performed in four stages. First, the pretest is performed to determine the children's quality of life. Second, the children with a quality of life score in the low or medium category are being involved in the experiment by receiving drawing therapy. Third, a posttest was done to identify the quality of life of children after the drawing therapy was completed. Fourth, a follow up in the form of measuring the quality of life of children was conducted a week after posttest.

\section{Research Participant}

The research participants in this study were children who experienced landslides natural disasters in Jelok Village, Purworejo Regency, Central Java Province, Indonesia, who met the following selection criteria: ages 8-11 years, experienced a landslide disaster at the scene of the disaster, were able to communicate well, do not experience severe mental disorders, have a low or moderate quality of life score based on the WHOQOL scale. Of the eight children in Jelok village who were in accordance with the age category above, five people were declared to meet the criteria, so their parents were asked for their consent to allow their children to take part in the study. Table 1 shows the profile of the research participants (a number of five children) involved in this study. 
Table 1

Profile of Research Participants

\begin{tabular}{llcl}
\hline Number & Name initial & Age (years) & Sexe \\
\hline 1 & A & 8 & Male \\
2 & B & 11 & Male \\
3 & C & 11 & Female \\
4 & D & 11 & Female \\
5 & E & 9 & Female \\
\hline
\end{tabular}

\section{Research Instrument}

This study uses an experimental design that also utilizes qualitative data to complement the quantitative data from the results of scale measurements, and to obtain a comprehensive picture of how the quality of life of children affected by this disaster is, before and after being given psychosocial interventions. The process of data collection is done by preparing a measure of quality of life, arranging a treatment/intervention module, as well as interview and observation guidelines.

The scale used to measure the quality of life in children experiencing natural disasters is adapted from The World Health Organization Quality of Life (WHO, 2004). WHOQOL is a scale consisting of four domains of quality of life, i.e. physical health, psychological aspects, social and spiritual relations. The WHOQOL-BREF scale is a development of WHOQOL-100, and has a validity of .89 - .95 and reliability of .66 - .87 (Sekarwiri, 2008). The total score of each domain is used to calculate the total score of the WHOQOL-BREF. This measure has been adapted to various languages, including Indonesian (WHO, 2004).

\section{Data Analysis}

Freidman Test was used to test the hypothesis of this study. This test is imposed on the same sample, in this case the experimental group was given a certain treatment and then the results were compared to the measurement results from the sample. The statistical analysis was carried out with the SPSS program (Statistical Product \& Service Solution) 16.0 for Windows. The qualitative data obtained from short interviews and observations on the children's quality of life based on their domains were analyzed descriptively and used as supplementary data to strengthen the quantitative findings.

\section{Research ethics, intervention procedures and psychosocial intervention modules}

The ethics permit for this research was obtained from the Research Ethics Committee (KEP) Universitas Ahmad Dahlan Number. 011706092, in August 2017. Because the participants in this study were children, informed consent was signed by the parents, and they were also involved during the assessment process until the intervention and follow up. To ensure information provided by the child, the researchers conducted an interview with the parents to verify the child's answers. The researchers were assisted by a therapist who has experience using a drawing therapy approach with children, and an observer who was in charge of recording all the processes during the intervention.

The drawing therapy module used in this study is modified from module on drawing therapy to reduce posttraumatic stress disorder in earthquake-affected children (Damayanti, 2012). The module is arranged based on (Buchalter, 2009) who states that drawing therapy activities consist of the three following stages: 
1) Warm up

This stage is about 5 - 10 minutes, aiming to help the children participants to be ready to draw, express their creativity, and increase their self-esteem, therefore, enabling them to create creative ideas in pictures. The therapist conveys that in an art therapy, expressions, thoughts and feelings, are emphasized. The focus is not whether the drawing images are right/wrong or good/bad.

2) Mindfulness

At this stage, the participants are asked to focus their attention on important events (sad or pleasant), they have experienced and let them feel again how they feel and think at that time. The task of the therapist is to convey positive and calming affirmations, which allow the child to remain calm even though their memory is asked to bring back their traumatic experience.

3) Drawing

In the drawing process, the participants are given the opportunity to communicate their thoughts, feelings, worries, problems, desires, hopes, and dreams in a fun way that is by scratching crayons and markers on drawing paper. At this stage, the therapist emphasizes that there is no good or bad assessment for the images drawn by the participants.

This study applies these three stages above in conducting psychosocial interventions for children victims of landslides. The implementation of drawing therapy interventions was carried out in four meetings with two hours in each meeting.

\section{Results}

Table 2 shows the Freidman analysis test on each domain and overall domain. The chisquare value of each domain and also of overall domain were significants. These results indicate the difference on quality of life among research participants before and after being treated with art therapy and in the follow up stage.

The data obtained from the follow up a week after the drawing therapy showed that the participants' scores on four quality of life domains remain increase significantly. The increasing score during pretest, posttest and follow up was also found in overall score.

Table 2

Friedman Test on Pretest, Post-Test, and Follow Up

\begin{tabular}{lcl}
\hline Domain & Chi-square & Significance \\
\hline Physical health & 10.000 & .007 \\
Psychological & 8.316 & .016 \\
Social & 9.579 & .008 \\
Environment & 9.579 & .008 \\
Overall domain & 10.000 & .007 \\
\hline
\end{tabular}

Based on the results of the analysis of each participant, it can be concluded that all participants in the experimental group experienced a varying increase in the scores of the quality of life. The details of the score increase can be seen in Figure 1. 


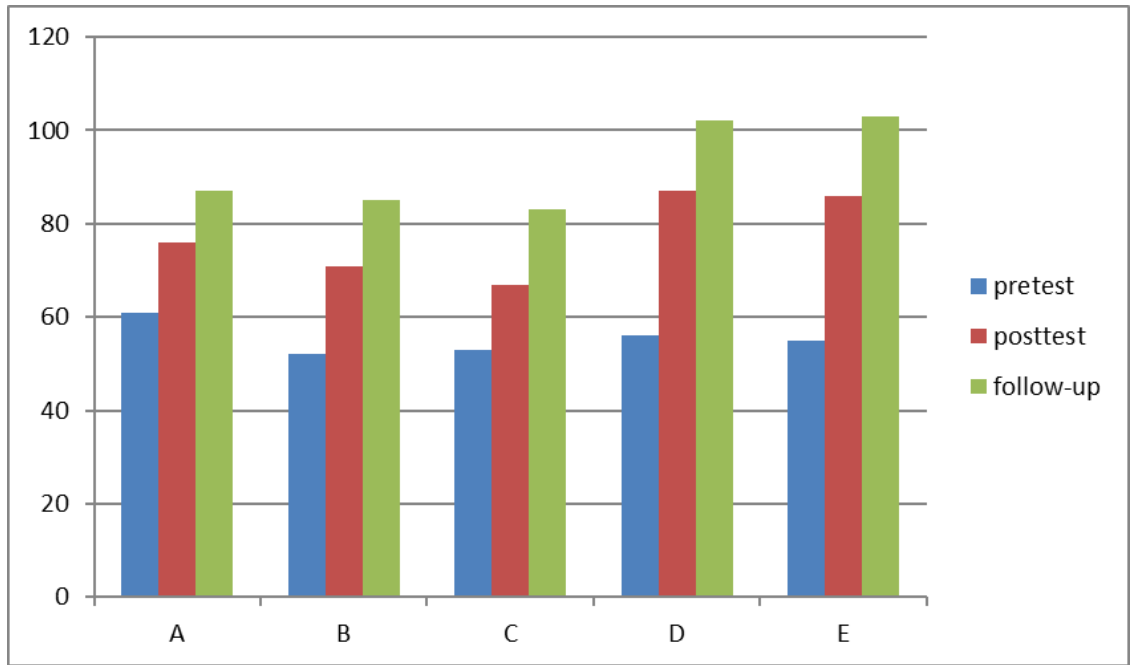

Figure 1. The total score chart of the experimental group's quality of life.

Figure 1 shows that all participants experienced an increase in their quality of life scores with a varying increase after being given drawing therapy (posttest) to follow up. These results illustrate that the increase in quality of life scores tends to persist up to the follow up phase, not only shortly after being given the drawing therapy. These results, therefore, reinforce that drawing therapy is able to improve the quality of life scores of the experimental group.

Based on the results of interviews with the children and their parents, there were also changes in the quality of life of children before and after being given a drawing therapy treatment as reflected in stories on the children's thoughts, behavior, and feelings. The following are some of the statements revealed by parents of the children who were participants in this study:

Before participating in in this drawing activity, my son was very quiet and passive, always wanting to be near to me for fear that there would be another disaster. He behaved like that since seeing and hearing a landslide in this village, Mis. Now he is active again playing with her/his friends (Mother of participant A).

In line with what was experienced by A, B's parent also stated that their son had undergone a change after attending the drawing therapy:

My son, B, said that now he is not afraid anymore, he wants to take the initiative to get active again. Even when the rain is falling, his emotional condition has also been normal, not as frightened as it was before participating in this study (Mother of participant B).

A similar experience was also felt by a grandmother who took care of participant $\mathrm{E}$ whose parents worked every day in the city. E was once a cheerful and high-spirited to go to school. However, after the landslide in her village, she turned into a moody child, not confident, and not enthusiastic about learning.

You see for yourself, right, Ms., when she was invited to join this program, E always refused to speak before the four friends finished talking ... she always asked for talk after they have all finished. That was not E before the landslide, Ms. ... Now she has revived her enthusiasm, she is already cheerful again and happy to learn again ... yes, after joining this program ... (Grandmother of participant E). 


\section{Discussion}

The results showed that drawing therapy was able to improve the quality of life of the experimental group as indicated by an increase in the quality of life scores of the research participants from the pretest to the posttest stage. The effect of drawing therapy on improving the quality of life of the children persists, even increasing as indicated by the increase in the quality of life scores at the follow up stage.

The three stages in the drawing therapy applied in this study are in in line with the direction of Buchalter (2009). These stages greatly help the process of conditioning the participants in entering therapeutic situations. The stage of "warm up" becomes "mental stretching" which facilitates the children to feel "accepted and respected" in groups that are built to do joint art activities. The mental stretching stage has made it easier for children to enter the stage of mindfulness, which requires the children to bring back their past including memories of the disaster event they experienced, but are led to accept it all as a unique life experience, other than their pleasant life experiences (Buchalter, 2009). The situation is then made concrete in the drawing expressions which essence is to provide space for children to convey their thoughts, feelings, hopes, and dreams in a fun way (Buchalter, 2009). This has helped the children to slowly re-enter their memory spaces on the traumatic events of the landslides they experienced, then expressed out through the drawing process, and then all were given positive meanings.

Researching about children's quality of life has been discussed by many experts as a complicated matter because the quality of life is very subjective (depending on each of the individual's perceptions), while children are research participants who are not considered reliable if they have to fill the scale or evaluate their quality of life (Eiser \& Morse, 2001). Therefore, it is often doubtful that children rely solely on measuring their quality of life, though, it is also impossible to measure the quality of life of children based solely on the answers of parents or caregivers, because each will have different meanings about the quality of life of the child (Eiser, 1997). Because of these considerations, the use of qualitative data as a means of "comparison" in evaluating the quality of life of children is carried out in this study. Qualitative data taken through various methods of data collection in this study proved to be very helpful for the researchers in convincing the results of the quantitative data collection on the quality of life of children reflected by parents in answering the scale of WHOQL-BREF. The collected qualitative data complements the results of the WHOQL-BREF scale measurement of children in accordance with the results of parent evaluations, thereby strengthening the validity of the quality of life data of the children in this study. The quotations from the interviews provide support on the results of the quantitative data analysis, which shows a significant change in the quality of life of the victims of landslides in the village of Jelok, Purworejo Regency.

The keywords in helping the children who experience traumatic events due to disasters are listening, clarifying, giving intense support, facilitating them to express through art symbols or game, and facilitating them to improve their bad imagination on traumatic events they experienced (Donnelly, 2003). Through games, including drawing activities, children can express verbally and non-verbally over painful feelings that are difficult for them to express, as well as their hopes and fantasies (Coates \& Schechter, 2004).

According to Chilcote (2007), art therapy, especially drawing, is quite effective in reducing post-traumatic anxiety. This method is considered to be quite beneficial 
psychologically and culturally, and is relatively easy to apply as an intervention for children. Malchiodi (2001) also states that drawing therapy to deal with children who experience trauma allows more for the children to be able to express their emotions and experiences non-verbally. Drawing can facilitate individuals to express their feelings by encouraging them to indirectly convey the stories from their pictures, and that is a way to translate individual experiences in a story. Rilley (Malchiodi, 2003) states that drawing is one form of externalization, self-projection, thoughts, and feelings, so it is very well used for means of releasing psychological burdens.

Some limitations in this study include, first, the design of one group pretest posttest that was applied in connection with the limited participants in the study, so no control group could be used as a comparison to test the effectiveness of drawing therapy. Second, the scale of measurement of the quality of life is not specific to be used as a measure for children, and the necessity that children must be accompanied by their parents in filling out the scale. In other words, the quality of life revealed is very likely to contain a bias in the perceptions of parents, and not purely the perceptions of the children. Third, the terrain is difficult to travel with the distance that is quite far and difficult to access by public transportation, so the therapist and the research team experience fatigue every time they visit the village of Jelok, so it is very likely that it has reduced the effectiveness of the therapy. Fourth, the follow up process is only done once with a distance of one week after the therapy, so the medium-term effects of drawing therapy are relatively unobserved. Therefore, future researchers can use experimental designs involving the experimental and the control group to see the effectiveness of the therapy used. The development of a quality of life scale adapted for children needs to be done so that measurements of the quality of life of children can be revealed according to the age of development.

\section{Conclusion}

The results of the study showed the influence of drawing therapy in improving the quality of life in children affected by landslides in Purworejo. The drawing therapy is proven to be able to help children express and overcome their emotional barriers that arise due to landslides, so the children's perceptions of their psychological condition, physical health, environment and social relations are better. Drawing therapy can be used as an alternative choice for psychologists in assisting children victims of disasters to improve their quality of life.

\section{Acknowledgment}

The authors would like to thank to the Directorate of Research and Community Service of the Republic of Indonesia's Ministry of Research, Technology and Higher Education, for providing this research grant (Letter of Grant Agreement on Implementation of Postgraduate Grant Research No. PPS-082 / SP3 / LPP-UAD / IV / 2017).

\section{References}

Buchalter, S. I. (2009). Art therapy techniques and applications. London: Jessica Kingsley Publishers.

Chilcote, R. L. (2007). Art therapy with child tsunami survivors in Sri Lanka. Art Therapy, 
24(4), 156-162. https://doi.org/10.1080/07421656.2007.10129475

Coates, S. W., \& Schechter, D. S. (2004). Preschoolers' traumatic stress post-9/11: Relational and developmental perspective. Psychiatruc Clinics of North America, 27, 473-490. https://doi.org/10.4324/9780203780527

Damayanti, E. S. (2012). Terapi menggambar untuk mengurangi gangguan stres pasca trauma pada anak korban gempa bumi (Drawing therapy to reduce post traumatic stress disorder among children affected by earthquakes). University of Ahmad Dahlan. $\quad$ Retrieved from http://digilib.uad.ac.id/penelitian/Penelitian/detail/64966/terapi-menggambar-untukmengurangi-gangguan-stres-pasca-trauma-pada-anak-korban-gempa-bumi

Data Informasi Bencana Indonesia (DIBI). (n.d.). Retrieved August 18, 2018, from http://dibi.bnpb.go.id/dibi/

Donnelly, C. L. (2003). Pharmacologic treatment approaches for children and adolescents with posttraumatic stress disorder. Child and Adolescent Psychiatric Clinics of North America, 12(2), 251-269. https://doi.org/10.1016/S1056-4993(02)00102-5

Eiser, C. (1997). Children's quality of life measures. Archives of Disease in Childhood, 77, 350-354.

Eiser, C., \& Morse, R. (2001). A review of measures of quality of life for children with chronic illness. Archives of Disease in Childhoodeases in Childhood, 84(3), 205211. https://doi.org/10.1136/adc.84.3.205

Jia, Z., Tian, W., He, X., Liu, W., Jin, C., \& Ding, H. (2010). Mental health and quality of life survey among child survivors of the 2008 Sichuan earthquake. Quality of Life Research, 19(9), 1381-1391. https://doi.org/10.1007/s11136-010-9703-8

Kar, N. (2009). Psychological impact of disasters on children. World J Pediatr, 5. https://doi.org/10.1007/s12519-009-0001-X

Madden, J. R., Mowry, P., Gao, D., Cullen, P. M., \& Foreman, N. K. (2010). Creative arts therapy improves quality of life for pediatric brain tumor patients receiving outpatient chemotherapy. $J$ Pediatri Oncol Nurs, 27(3), 133-145. https://doi.org/10.1177/1043454209355452

Malchiodi, C. A. (2001). Using drawing as intervention with traumatized children. Trauma and Loss: Research and Interventions, 1(1).

Malchiodi, C. A. (2003). Handbook of art therapy. Psychiatric Services (Vol. 54). https://doi.org/10.1176/appi.ps.54.9.1294-a

Malchiodi, C. A. (2005). Expressive therapies. (C. A. Malchiodi, Ed.). New York: The Guilford Press.

Nader, K. (2004). Treating methods for childhood trauma. New York: The Guilford Press.

Sekarwiri, E. (2008). Hubungan antara kualitas hidup dan sense of community pada warga DKI Jakarta yang tinggal di daerah rawan banjir (The correlation of quality of life with sense of community among DKI Jakarta residents who live in flood-prone area). Universitas Indonesia, Depok.

Somasundaram, D. J., \& Van de Put, W. A. C. M. (2006). Management of trauma in special populations after a disaster. The Journal of Clinical Psychiatry, 67 Suppl 2, 64-73.

Talwar, S. (2007). Accessing traumatic memory through art making: An art therapy trauma protocol (ATTP). Arts in Psychotherapy, 34(1), 22-35. https://doi.org/10.1016/j.aip.2006.09.001

UNISDR. (n.d.). Retrieved August 1, 2018, from https://www.unisdr.org/partners/countries/idn

Varni, J. W., Limbers, C. A., \& Burwinkle, T. M. (2007). Impaired health-related quality 
of life in children and adolescents with chronic conditions: A comparative analysis of 10 disease clusters and 33 disease categories/severities utilizing the PedsQL ${ }^{\mathrm{TM}} 4.0$ Generic Core Scales. Health and Quality of Life Outcomes, 5. https://doi.org/10.1186/1477-7525-5-43

Varni, J. W., Seid, M., \& Rode, C. A. (1999). The PedsQL: Measurement model for the pediatric quality of life inventory. Medical Care, 37(2), 126-139. Retrieved from http://www.ncbi.nlm.nih.gov/pubmed/10024117

WHO. (1996). WHOQOL-BREF. Retrieved from https://www.who.int/mental_health/media/en/76.pdf

WHO. (1997). WHOQOL Measuring Quality of Life. Retrieved from https://www.who.int/mental_health/media/68.pdf

WHO. (2004). The World Health Organization Quality Of Life (WHOQOL)-BREF. Retrieved from https://www.who.int/substance_abuse/research_tools/en/english_whoqol.pdf 